\title{
Global patterns of interaction specialization in bird-flower networks
}

Thais B. Zanata ${ }^{1,2,3, *}$ (D) | Bo Dalsgaard ${ }^{3}$ | Fernando C. Passos ${ }^{4}$ | Peter A. Cotton ${ }^{5}$ | James J. Roper ${ }^{1,6}$ | Pietro K. Maruyama7 | Erich Fischer ${ }^{8}$ | Matthias Schleuning ${ }^{9}$ | Ana M. Martín González ${ }^{3,10}$ | Jeferson Vizentin-Bugoni ${ }^{11,12}$ | Donald C. Franklin ${ }^{13}$ | Stefan Abrahamczyk ${ }^{14,15}$ | Ruben Alárcon ${ }^{16}$ | Andréa C. Araujo ${ }^{17}$ | Francielle P. Araújo ${ }^{18}$ | Severino M. de. Azevedo-Junior ${ }^{19}$ | Andrea C. Baquero ${ }^{3}$ | Katrin Böhning-Gaese ${ }^{9,20}$ | Daniel W. Carstensen ${ }^{3}$ | Henrique Chupil ${ }^{21}$ | Aline G. Coelho ${ }^{22}$ | Rogério R. Faria ${ }^{23}$ | David Hořák ${ }^{24}$ | Tanja T. Ingversen ${ }^{25}$ | Štěpán Janeček ${ }^{24,26}$ | Glauco Kohler ${ }^{1,27}$ | Carlos Lara ${ }^{28}$ | Flor M. G. Las-Casas ${ }^{29}$ | Ariadna V. Lopes ${ }^{30}$ | Adriana O. Machado ${ }^{31}$ | Caio G. Machado ${ }^{22}$ | Isabel C. Machado ${ }^{30}$ | María A. Maglianesi ${ }^{9,32}$ | Tiago S. Malucelli ${ }^{1,2}$ | Jayasilan Mohd-Azlan ${ }^{13,33}$ | Alan C. Moura ${ }^{22}$ | Genilda M. Oliveira ${ }^{34}$ | Paulo E. Oliveira $^{31}$ | Juan Francisco Ornelas ${ }^{35}$ (D) | Jan Riegert ${ }^{36}$ | Licléia C. Rodrigues $^{37}$ | Liliana Rosero-Lasprilla $^{38}$ | Ana M. Rui ${ }^{39}$ | Marlies Sazima ${ }^{7}$ | Baptiste Schmid ${ }^{40}$ | Ondřej Sedláček ${ }^{24}$ | Allan Timmermann ${ }^{41}$ | Maximilian G. R. Vollstädt ${ }^{9,20 ~ \mid ~}$ Zhiheng Wang $^{42}$ | Stella Watts ${ }^{43}$ | Carsten Rahbek ${ }^{3,44}$ | Isabela G. Varassin²

\footnotetext{
${ }^{1}$ Programa de Pós-Graduação em Ecologia e Conservação, Universidade Federal do Paraná, Curitiba-PR, Brazil

${ }^{2}$ Laboratório de Ecologia Vegetal, Departamento de Botânica, Universidade Federal do Paraná, Curitiba, Brazil

${ }^{3}$ Center for Macroecology, Evolution and Climate, Natural History Museum of Denmark, University of Copenhagen, Copenhagen, Denmark

${ }^{4}$ Laboratório de Biodiversidade, Conservação e Ecologia de Animais Silvestres, Departamento de Zoologia, Universidade Federal do Paraná, Curitiba, Brazil

${ }^{5}$ Marine Biology \& Ecology Research Centre, University of Plymouth, Plymouth, UK

${ }^{6}$ Graduate Program in Ecosystem Ecology, Universidade Vila Velha, Vila Velha, Brazil

${ }^{7}$ Departamento de Biologia Vegetal, Instituto de Biologia, Universidade Estadual de Campinas, Campinas, Brazil

${ }^{8}$ Centro de Ciências Biológicas e da Saúde, Universidade Federal de Mato Grosso do Sul, Campo Grande, Brazil

${ }^{9}$ Senckenberg Biodiversity and Climate Research Centre (BiK-F), Frankfurt (Main), Germany

${ }^{10}$ Pacific Ecoinformatics and Computational Ecology Lab, Berkeley, CA, USA

${ }^{11}$ Programa de Pós-Graduação em Ecologia, Universidade Estadual de Campinas (Unicamp), Campinas, Brazil

${ }^{12}$ University of Illinois at Urbana-Champaign, Urbana, IL, USA

${ }^{13}$ Research Institute for Environment \& Livelihoods, Charles Darwin University, Darwin, NT, Australia

${ }^{14}$ Nees Institute for Biodiversity of Plants, University of Bonn, Bonn, Germany

${ }^{15}$ Institute of Systematic and Evolutionary Botany, University of Zurich, Zurich, Switzerland

${ }^{16}$ Biology Program, California State University Channel Islands, Camarillo, CA, USA

${ }^{17}$ Laboratório de Ecologia, Centro de Ciências Biológicas e da Saúde, Universidade Federal de Mato Grosso do Sul, Campo Grande, Brazil

${ }^{18}$ Universidade Estadual do Rio Grande do Sul, São Francisco de Paula, Brazil

${ }^{19}$ Department of Biology, Rural Federal University of Pernambuco, Recife, Brazil
} 
${ }^{20}$ Institute for Ecology, Evolution and Diversity, Goethe University, Frankfurt am Main, Germany

${ }^{21}$ Programa de Pós-Graduação em Zoologia, Instituto de Pesquisas Cananéia, Cananéia, Brazil

${ }^{22}$ Laboratório de Ornitologia, Departamento de Ciências Biológicas, Universidade Estadual de Feira de Santana, Feira de Santana, Brazil

${ }^{23}$ Campus de Aquidauana, Universidade Federal de Mato Grosso do Sul, Aquidauana, Brazil

${ }^{24}$ Department of Ecology, Faculty of Science, Charles University in Prague, Praha 2, Czech Republic

${ }^{25}$ Department of Ecology \& Genetics, Institute of Biological Sciences, University of Aarhus, Aarhus, Denmark

${ }^{26}$ Institute of Botany, Czech Academy of Sciences, Třeboň, Czech Republic

${ }^{27}$ Instituto Nacional de Pesquisas da Amazônia, Manaus, Brazil

${ }^{28}$ Centro de Investigación en Ciencias Biológicas, Universidad Autónoma de Tlaxcala, Tlaxcala, México

${ }^{29}$ Laboratory of Ecology, Systematics and Evolution of Birds, Federal University of Pernambuco, Recife, Brazil

${ }^{30}$ Departamento de Botânica, Universidade Federal de Pernambuco, Recife, Brazil

${ }^{31}$ Instituto de Biologia, Universidade Federal de Uberlândia, Uberlândia, Brazil

${ }^{32}$ Vicerrectoría de Investigación, Universidad Estatal a Distancia (UNED), San José, Costa Rica

${ }^{33}$ Department of Zoology, Faculty of Resource Science and Technology, Universiti Malaysia Sarawak, Sarawak, Malaysia

${ }^{34}$ Instituto Federal de Brasília, Brasília, Brazil

${ }^{35}$ Departamento de Biología Evolutiva, Instituto de Ecología, AC, Xalapa, México

${ }^{36}$ Department of Zoology, Faculty of Science, University of South Bohemia, České Budẽjovice, Czech Republic

${ }^{37}$ Laboratório de Ornitologia, Departamento de Zoologia, ICB, Universidade Federal de Minas Gerais, Belo Horizonte, Brazil

${ }^{38}$ Escuela de Ciencias Biológicas, Grupo de Investigación Biología para la Conservación, Universidad Pedagógica y Tecnológica de Colombia, Tunja, Colombia

${ }^{39}$ Departamento de Ecologia, Zoologia e Genética, Instituto de Biologia, Universidade Federal de Pelotas, Capão do Leão, Brazil

${ }^{40}$ Swiss Ornithological Institute, Sempach, Switzerland

${ }^{41}$ Department of Bioscience, Aarhus University, Aarhus, Denmark

${ }^{42}$ Department of Ecology and Key Laboratory for Earth Surface Processes of the Ministry of Education, College of Urban and Environmental Sciences, Peking University, Beijing, China

${ }^{43}$ Landscape and Biodiversity Research Group, Department of Environmental and Geographical Sciences, University of Northampton, Northampton, UK

${ }^{44}$ Department of Life Sciences, Imperial College London, Ascot, UK

\section{Correspondence}

Thais B. Zanata, Laboratório de Ecologia Vegetal, Departamento de Botânica, Universidade Federal do Paraná, Centro Politécnico, Curitiba-PR, Brazil.

Email: thaisbzanata@gmail.com

\section{Funding information}

CAPES Foundation, Grant/Award Number: 8105/2014-6, 8012/2014-08; CNPq, Grant/ Award Number: 309453/2013-5, 445405/ 2014-7; Czech Science Foundation (project no. 14-36098G); British Ornithologists' Union; Wolfson College, University of Oxford; FAPESP, Grant/Award Number: 2015/21457-4; FAPEMIG; FUNDECT; Oticon Fonden Denmark; The Danish Council for Independent Research Natural Sciences; University of Aarhus; CACyPIUatx-2016GK; FACEPE; OeAD; FAPESB; CONICIT; MICIT; CCT; UNED; OTS; DAAD; DFG; Hesse's Ministry of Higher Education, Research, and the Arts

Editor: Holger Kreft

\section{Abstract}

Aim: Among the world's three major nectar-feeding bird taxa, hummingbirds are the most phenotypically specialized for nectarivory, followed by sunbirds, while the honeyeaters are the least phenotypically specialized taxa. We tested whether this phenotypic specialization gradient is also found in the interaction patterns with their floral resources.

Location: Americas, Africa, Asia and Oceania/Australia.

Methods: We compiled interaction networks between birds and floral resources for 79 hummingbird, nine sunbird and 33 honeyeater communities. Interaction specialization was quantified through connectance $(C)$, complementary specialization $\left(\mathrm{H}_{2}{ }^{\prime}\right)$, binary $\left(Q_{B}\right)$ and weighted modularity $(Q)$, with both observed and null-model corrected values. We compared interaction specialization among the three types of bird-flower communities, both independently and while controlling for potential confounding variables, such as plant species richness, asymmetry, latitude, insularity, topography, sampling methods and intensity.

Results: Hummingbird-flower networks were more specialized than honeyeaterflower networks. Specifically, hummingbird-flower networks had a lower proportion of realized interactions (lower $\mathrm{C}$ ), decreased niche overlap (greater $\mathrm{H}_{2}{ }^{\prime}$ ) and greater modularity (greater $Q_{B}$ ). However, we found no significant differences between hummingbird- and sunbird-flower networks, nor between sunbird- and honeyeaterflower networks. 